\title{
Micro and Nanoscale Studies of Shock Features within the Chelyabinsk LL5 Meteorite.
}

\author{
S. S. Rout ${ }^{1,2}$ and P. R. Heck ${ }^{1,2}$ \\ 1. Robert A. Pritzker Center for Meteoritics and Polar Studies, The Field Museum of Natural History, \\ 1400 S Lake Shore Drive, Chicago, IL 60605, USA. \\ 2. Chicago Center for Cosmochemistry, The University of Chicago, 5734 S Ellis Avenue, Chicago, IL \\ 60637, USA.
}

Shock effects within meteorites are the products of impacts and collisions in the asteroid belt that eventually led to the ejection of the meteorite from its parent body. These collisions produce shock waves, which in turn lead to formation of high-pressure phases and deformation features within the host meteorite. The $(\mathrm{P}, \mathrm{T}, \mathrm{t})$ history of the shock process can be deduced by studying these high-pressure phases which are produced either by solid state transformation or by crystallization of the shock melt [1]. Although detailed studies of shock effects within various highly shocked (S5-S6) L chondrites have been carried out in order to understand the $\mathrm{P}$ and $\mathrm{T}$ conditions during the impacts events [e.g., 1,2], very few studies have been done on LL and $\mathrm{H}$ chondrites $[3,4]$. Improved knowledge of shock effects on these other ordinary chondrites is desirable because of their different origin.

Here, we present preliminary results from the Chelyabinsk meteorite that exploded over the Chelyabinsk area of Russia on February 15, 2013. Hundreds of fragments were collected subsequent to the airblast and were classified as LL5 ordinary chondrites [5] with impact melt rock clasts and shock-darkened lithologies. The LL5 classification was challenged by [6], who stated that Chelyabinsk is a complex genomict breccia that also contains LL6 lithologies. In this study we search for high pressure mineral phases in impact melt veins, found within a shock-darkened fragment.

We prepared a polished section from Field Museum Chelyabinsk specimen ME 6050 and used the Field Museum's Zeiss Evo 60 SEM equipped with an Oxford EDS system to image the melt veins and look for characteristic shock features for later Raman and FIB/TEM studies. The texture of the melt veins and the composition of phases both inside and outside the veins were studied using SEM/EDS. High pressure mineral polymorphs form generally near or within the melt veins. For quantitative elemental SEM/EDS analyses the following standards were used: diospide (Ca), synthetic forsterite $(\mathrm{Mg})$, olivine from the Springwater meteorite (Fe), San Carlos olivine $(\mathrm{Mg}, \mathrm{Si})$, microcline $(\mathrm{K})$, rutile (Ti), corundum (Al), chromite $(\mathrm{Cr})$ and Albite $(\mathrm{Na})$. Raman spectra from selected region were taken with an Acton TriVista confocal Raman spectrometer at Northwestern University using a $514.5 \mathrm{~nm}$ laser operating at 3-5 $\mathrm{mW}$. The laser spot size on the sample was 1 micron and care was taken to prevent overheating of the sample under the laser beam.

The studied meteorite fragment contains abundant shock melt veins ranging in thickness from $\sim 50 \mu \mathrm{m}$ to $\sim 1 \mathrm{~mm}$ and two melt pools. Most of the melt veins contain abundant silicate clasts surrounded by a matrix of sulfide and metal (Fig. 1). Sometimes the clasts are rounded, indicating that they have been partially resorbed. Some veins have low abundances of opaque phases with most of the opaque phases occurring as rounded or partly irregular blebs. A thin layer is present at the contact between one of the melt veins and the host meteorite (Fig. 1). It contains small $(1-10 \mu \mathrm{m})$ rounded metal and sulfide blebs and very fine-grained crystals. The melt pool contains some large lithic silicate clasts, small euhedral zoned crystals $(\sim 2-4 \mu \mathrm{m})$, quenched melt, large rounded metal and sulfide blebs and melt matrix (Fig. 
1). The composition of olivine ( $\left.\mathrm{Fa}_{29-30}\right)$, pyroxene $\left(\mathrm{Fs}_{24.5} \mathrm{Wo}_{1.5}\right.$ and $\left.\mathrm{Fs}_{9-10} \mathrm{Wo}_{44.5-45}\right)$, and feldspar $\left(\mathrm{Ab}_{82-}\right.$ $\left.84 \mathrm{Or}_{6-10}\right)$ within the melt vein and the surrounding matrix is almost similar. The analyzed quenched glass is rich in $\mathrm{Na}, \mathrm{Mg}, \mathrm{Al}$ and $\mathrm{Ca}$.

Overall the Chelyabinsk meteorite has suffered significant shock (S4) and contains numerous melt veins filled with Fe,Ni-metal and troilite. Our preliminary SEM-EDS studies did not show the presence of any high-pressure phases within the melt veins but this does not rule out their presence as most of the high pressure phases, formed by solid state transformation, have similar composition as their host mineral. Any high-pressure phase that would have crystallized within the melt vein can only be identified by later TEM studies. Recent Raman spectroscopic studies found the presence of high pressure polymorph of merrilite within one vein [7]. Most of the studied veins have dominant unmelted mineral clasts whereas some others along with the melt pools show clear signs of complete melting and unmixing of silicate and metal-sulfide melt. These veins, with signatures of complete melting, will be later studied by TEM.
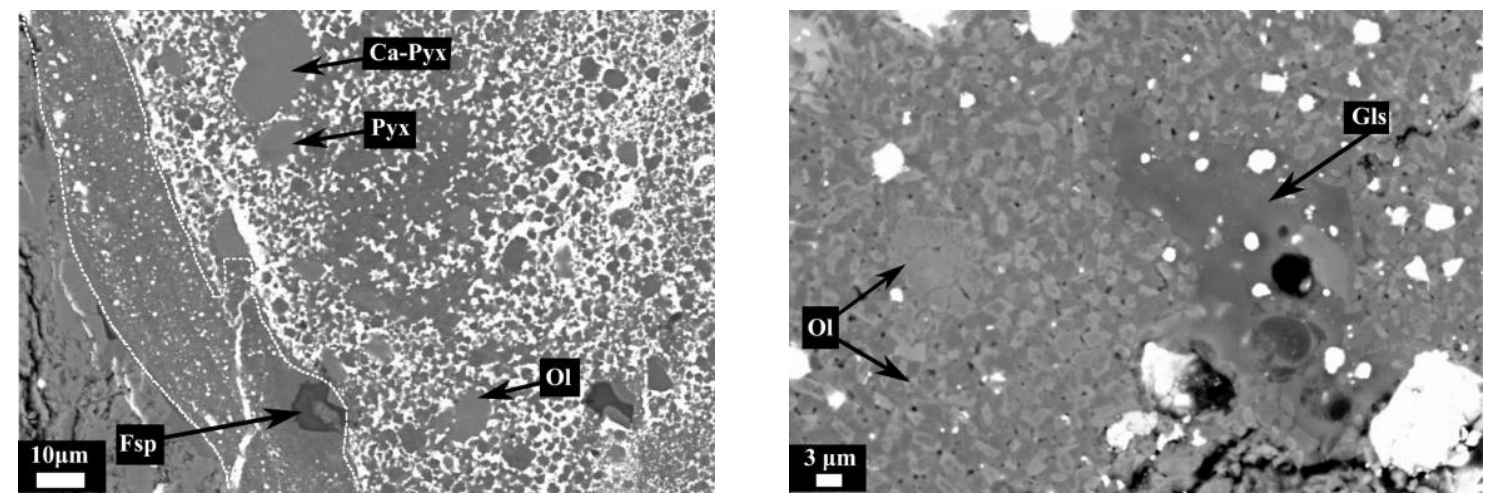

Figure 1. BSE image of the melt vein (left) and a melt pool (right) within the Chelyabinsk meteorite. Numerous rounded and irregularly shaped mineral fragments are seen within the melt surrounded by Fe,Ni-metal and Fe-sulfide. A thin layer is present in the contact between the melt vein and the host meteorite matrix (indicated by dashed lines). The melt pool has numerous euhedral crystals of olivine within a melt matrix. A quenched glass (Gls) along with white rounded Fe,Ni-metal and Fe-sulfide is also present. $\mathrm{Ol}=$ olivine; $\mathrm{Ca}-\mathrm{Pyx}=\mathrm{Ca}$-rich pyroxene; Pyx $=$ low-Ca pyroxene; Fsp = feldspar.

\section{References}

[1] T. G. Sharp and P. S. DeCarli in "Meteorites and the Early Solar System II", ed. D. S. Lauretta and

H. Y. McSween (The University of Arizona Press, Arizona) p. 653-678.

[2] P. Gillet et al, Geological Survey of America Special Papers, 421 (2007), p57-82.

[3] A. Bischoff, Lunar and Planetary Science Conference XXXIII (2002), Abstract\# 1264.

[4] M. Miyahara et al, Earth and Planetary Science Letters, 373 (2013), p102-108.

[5] E. M. Galimov et al, Geochemistry International, 51 (2013), p522-539.

[6] A. Bischoff et al, Meteoritics and Planetary Science, 48 (2013), A61.

[7] J. M. Trigo-Rodriguez et al, 45 ${ }^{\text {th }}$ Lunar and Planetary Science Conference (2014), Abstract\# 1729.

[8] The authors acknowledge funding from the Tawani Foundation and from W. H. Ganz III. We thank

T. Boudreaux for providing samples of Chelyabinsk, the National Museum of Natural History of the Smithsonian Institution and I. Steele, The University of Chicago, for providing analytical standards. We thank B. Strack for maintenance of the SEM. This work made use of the EPIC facility (NUANCE Center-Northwestern University) and the Nanoscale Science and Engineering Center, both supported by the National Science Foundation; the state of Illinois; and Northwestern University. 